\title{
Closing the Loop: Integrating 3D Printing with Engineering Design Graphics for Large Class Sizes
}

\author{
James Baleshta, Peter Teertstra, and Benny Luo \\ Department of Mechanical and Mechatronics Engineering, University of Waterloo, \\ jim.baleshta@uwaterloo.ca, peter.teertstra@uwaterloo.ca, benny.luo@waterloo.ca
}

\begin{abstract}
Closing the loop by completing all stages in the design process is an important experience for every engineer. There is significant experiential merit, for example, in providing first year students with a design challenge that starts with a blank sheet of paper and ends with reflective observation of their fabricated model. The advent of $3 D$ printing has "game changer" potential as a vehicle for this experience, but it has limitations, especially for large class sizes.

An activity was devised to complete the design loop using $3 D$ printing. This initiative effectively overcame the limited throughput rates and high material costs associated with $3 D$ printing for 427 students.

Activity outcomes were assessed via an exit survey, including whether students perceived differences between their CAD and $3 D$ physical models. Students enjoyed the experience, and grew from it. The outcomes from this initiative along with the lessons learned may be of use to other instructors considering a similar experiential path.
\end{abstract}

Keywords: 3D printing, experiential learning, first year graphics and design, large class sizes.

\section{INTRODUCTION}

The "loop" of mechanical engineering design closely aligns with educational psychologist David Kolb’s [1] experiential learning cycle: experimentation, concrete experience, reflective observation and abstract conceptualization [2]. This alignment becomes apparent as students design a device, build it (or have it built) and, upon reflection of the experience, improves their practices for a second iteration of design. However, Doyle, Smith and Ieta [3] stated that, due to time constraints and large class sizes, there is "rarely" time for verification and iteration of CAD model designs. They noted that students become adept at using CAD programs but are often unaware of how well their designs will then function. Their methodology of using system modeling via simulation software to close the design loop was met with positive student feedback. They reported that this made course material more appealing to students and allowed the instructor to proceed much deeper into the "design dialogue”. Livesay and Rogge of the Rose-Hulman Institute of Technology [4] implemented a vertical mentoring program in biomedical engineering as another means of closing the loop in design. Upper year students would mentor junior design projects through a complete cycle of the design process. This was viewed as an important pre-cursor for future term, open-ended, complex design projects.

This paper describes the effort to leverage 3D printing as an expedient means to close the design loop for a large class size of first-term engineering students. 3D printing is an additive manufacturing process that creates components through a fusion of deposited layers. This differs from subtractive manufacturing processes that use cutting machines (e.g. lathes, mills) to remove material to the final desired shape. 3D printing has low fixed costs, does not require expensive tooling [5], and shortens the path from conception to reality. In an interesting paper, Jaksic (2014) [6] cites the role of low cost 3D printers for experiential learning in engineering education at Colorado State University - Pueblo. Instructors incorporated 3D printing applications in 12 courses throughout the mechatronics and industrial engineering curricula. During the freshman (first) year, students in the Engineering Graphics course print "only a couple of objects" as 3D visualization aids and, in the Introduction to Engineering course of 20 to 25 students, they print a pre-existing (bracelet) part. Although the use of 3D prints enhanced the two courses, students did not individually have the opportunity to do creative project 3D printing. The authors encouraged more exposure to this technology and, as projects became more challenging during later terms, they also noted a high level of student engagement with 3D printing. It was suggested that the technology may increase students' "intellectual curiosity and grit", improving success in engineering education. There was motivation for a similar change in the curriculum at University of Waterloo (UWaterloo).

Students enter the Mechanical and Mechatronics (MME) program at UWaterloo with expectations on the early stages of their engineering education. Although many are lacking in practical, hands-on, and technical 
design skills [7], students hope to acquire these as early as first year. In reality, they are faced with complementary math and science courses that comprise the greater part of the first term curriculum. Opportunities to address the students' desire for practical activities lie primarily within the first year concepts course. The engineering graphics and design section of this course introduces students to engineering graphics concepts and technical drawing creation while integrating components on lateral thinking, the engineering design process, and other design topics. It is important that students develop expertise in computeraided design as many will soon be required to use CAD during their co-operative work terms.

It was therefore decided that the first year concepts course should be modified to provide students with a more realistic engineering experience during their first term. The overarching objective was to integrate the students' newly acquired skills in graphics and design with a creative closed-loop endeavor so that they could apply and grow their budding expertise and show what they can accomplish. An activity was therefore designed to give students an interesting end-of-design fabricated device while feasibly meeting the time and resource demands for a large number of students.

Engineering graphics instructor, Baleshta, observed that students enjoy opportunities to apply their creativity in the first year concepts course. Based on his experience, he noted the value in seeing a physical manifestation of the design efforts after completing the graphical design stage. This value comes from a reflection on the fabricated outcome as it is then possible to assess how the designer's conceptualization of the artifact corresponds with the manufactured product. Reflective observation in experiential learning is widely supported in literature [8]. It was desirable to give first term MME students an early exposure to this tactile experience but also daunting due to the large number of students involved (four class divisions totaling to 427 students). The advent of sophisticated 3D printing capabilities within the Faculty of Engineering at UWaterloo created a potential (but formidable) opportunity to integrate component fabrication into the first year engineering design graphics course.

The solutions considered for a design-fabricate activity were back-driven from a desire to leverage the 3D printer capabilities at UWaterloo. A challenge remained to find a "doable" 3D printer project that would be motivating, appropriate in terms of cost and equipment, and that had a high rate of printer throughput.

The selected methodology provided students with an opportunity for expansive experiential learning through an integration of ongoing course lessons and newly obtained technology while employing methods to assess the substantive outcomes of this initiative. The results from this methodology for a first time offering showed that it was possible to successfully host a large scale 3D printing initiative. However, this was contingent on having suitable 3D printing capabilities in place and choosing a modest fabrication in terms of physical size, material volume requirements and pricing. Student surveys showed positive outcomes and, most importantly, they discovered that there are conceptual gaps between a computer generated virtual model and a physical fabrication of a mechanical device. Understanding the value, but also the limitations of a virtual CAD model is an important lesson to take into future academic terms, and the work place.

\section{BACKGROUND}

\subsection{Desire for "Real” Engineering in First Year}

Many students enter the MME stream at UWaterloo with a dearth of practical mechanical skillsets and want to complete their first term feeling that they accomplished real engineering, expanded these skillsets, and had outlets for their creativity.

The math and science courses that dominate the first year curriculum are taught by faculty members from other departments, who are non-engineers. The sole course taught by departmental instructors, who are practicing engineers, is the first year concepts course. This course includes a concurrent section on engineering graphics and design (EG\&D). Continued efforts have been made within EG\&D to address and improve the aforementioned lack of student technical experience. This has increased the focus on the design portion of these sessions. To improve student awareness of the implicit practicalities associated with the creation of engineering drawings, practical demonstrations were first developed and presented in class. A case study on the design of a medical device was also implemented to introduce the engineering design process [9]. An "Engineering Ideas Clinic ${ }^{\mathrm{TM}}$ " [10] activity was recently added to give all MME first year students direct hands-on experience with drilling (through-holes, countersinks, counterbores), thread tapping, and assembly. The fabrication (a keychain) is then owned by each student as a keepsake for reflection. This seemingly modest initiative, when applied to 427 students, is at the limit of what can be viably student-machined during the first term of EG\&D [7]. It gives a clear awareness of the challenges associated with a large-scope, student fabrication project. A significant "design and build" project for this number of first term engineers would be untenable considering the current academic curriculum and resource limitations at UWaterloo.

\subsection{The Advent of 3D Printing}

Although additive manufacturing or 3D printing technologies have been in use for decades [6][11], it wasn't until the advent of affordable computers, 3D 
modeling software, and 3D printing systems, that additive manufacturing became widely adopted within engineering education. Educational institutions, both secondary and post-secondary, are purchasing consumer-level and professional-grade additive manufacturing systems for use by instructors and students. The usage models can vary from allowing students free access to consumer-level equipment in an exploration space, through to working with trained operators and higher-end equipment. Regardless of how the technology is utilized, the general agreement is that having access to affordable $3 \mathrm{D}$ printing is beneficial to students [6][12]. Whether they are making prototypes or final parts for academic or personal projects, it allows students to quickly and easily fabricate their designs with minimum time and cost, while learning important design related skills. Tailoring a design for subsequent 3D printing is a worthwhile skill with growing applications. According to Barry Berman's paper “3D Printing: The New Industrial Revolution" [5], it is estimated that over $20 \%$ of 3D prints currently produce final products (as opposed to prototypes) and is predicted to rise to $50 \%$ by 2020 . This is indicative of the future engineering demands that this modern engineering tool will have on today's students.

\section{RESULTS AND DISCUSSION}

\subsection{Integrating 3D Printing with Engineering Graphics and Design: Activity Selection}

The 3D Print Centre at the University of Waterloo is a campus-wide resource for students, staff, and faculty where they can access production-grade additive manufacturing equipment at a cost which is significantly lower than the industry standard. Originally based on a single Stratasys 360mc 3D printer utilizing fused deposition modeling (FDM) technology, the 3D Print Centre started as a facility that supported the Faculty of Engineering student teams in the Sedra Student Design Centre. Interest grew in undergraduate engineering classes, and soon the 3D Print Centre expanded to support part production for class projects, capstone design projects, and entrepreneurial activities.

The 3D Print Centre is staffed by undergraduate co-op students who operate the machinery and provide feedback as well as advice for optimization of design for additive manufacturing. Recently adding a second 360mc machine and a Dimension 1200 FDM printer in addition to equipment to fabricate printed circuit boards, the 3D Print Centre has expanded to provide campus wide support.

To develop the EG\&D activity, discussions were first held with the 3D Print Centre management. They were receptive but challenged by the prospect of a high throughput 3D printing project. Their efforts and success at obtaining printing materials at reasonable cost, determining the print scheduling demands and forecasting throughput rates made the project tentatively feasible. Once it was decided that a 3D printing project could be incorporated within the first term, attention then focused on finding a project that would interest the majority of students. It is readily apparent to any instructor that students, with very few exceptions, possess a cellular phone. Cell phones hold significant student value and an accessory for these devices could have mass appeal. A cell phone case was considered but was dropped in favour of a cell phone holder (stand) since a holder would intrinsically allow a wider range of creative design solutions. An analysis was conducted to verify that solutions could be found within the material volume constraint $\left(2 \mathrm{in}^{3} / 32 \mathrm{~cm}^{3}\right)$ set by the 3D Print Centre.

This activity would be introduced into an already demanding course schedule, so means were sought to minimize the project's workload impact. The project replaced (but integrated components of) a freehand drawing assignment. The drawing assignment was given near the end of the term and required students to incorporate various aspects of the course. The replacement project held a similar weight and objective. Other factors also needed consideration. An end-of-term project would not be ideal as students face other projects and increased curriculum demands during this time. In conjunction, a late-term flood of 3D print files generated by this activity would unfavourably extend the printing completion date to beyond the end of the academic term. Though an early activity start would be able to address these issues, some of the knowledge and techniques required to complete the component design are taught towards the end of the term. As a result, the project was rolled out to progress as the course progressed. In this way, early stage activities could commence and necessary lessons would follow. The late-term spike of work could also be avoided. The activity was introduced over a three week period (term weeks 9 to 11), and receivables were compulsory at the end of each stage. Requiring students to develop their design over a multi-week period allowed for reflection and revisions that would not be possible during the typical "panic" of rear-loaded time management (i.e. where everything is done within a short timeframe with a rushed manner to meet the final deadline).

\subsection{Activity Details}

Stage One: The premise of the activity was that "a company" desires a trade show booth giveaway, specifically a cell phone holder. They asked for competitive designs in the form of preliminary sketches during this initial stage. The students (as theoretical owners of a startup 3D printing company) are given a week to provide sketches for two alternative designs, with an additional sketch that shows their chosen alternative in greater detail. In keeping with the design process, they were also asked to compile a list of functions and design 
specifications to which the holder should conform. Three constraints were set by "the company". The first was a component volume limit of $2 \mathrm{in}^{3}$. This limitation was actually set by the 3D Print Centre but was presented to the students as an effort by the client to minimize future fabrication costs. The other constraints were a cell phone positional angle for good in-stand visibility (Fig. 1), and a one-piece design to rest on a desktop or bedside table.

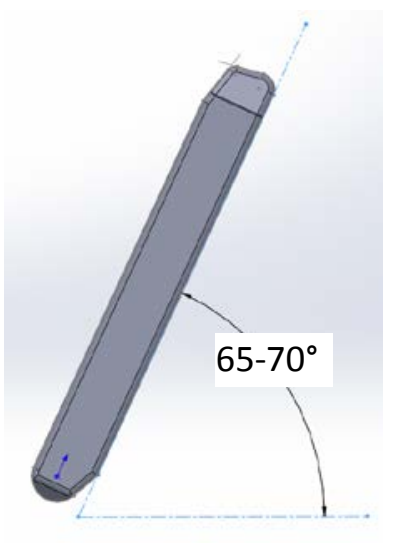

Fig. 1. Position constraint of $65^{\circ}-70^{\circ}$

Students used their own cell phones for measurements. They were urged to stay off the internet, as looking at preexisting designs would diminish their creativity. They were also cautioned that their chosen sketch would eventually require conversion to a 3D solid model; therefore their design solution should be within their range of solid modeling expertise.

Stage Two: The premise during this stage was that the company liked the conceptual sketches from the previous week and wished to see a solid model created. SolidWorks ${ }^{\mathrm{TM}}$ was used as the CAD software. The solid models were presented in hard copy form and annotated with notes that students felt were valuable. Dimensioned drawings were not required as they were not directly needed for fabrication. (It should be noted, however, that dimensioned drawings are still a very important aspect of engineering graphics and are taught, assigned and assessed by separate means.) The students were required to indicate the net volume of their part and that it met the maximum volume constraint. This volume determination, which otherwise could be complicated due to complex part shapes, is readily determinable using the mass property evaluation feature of SolidWorks ${ }^{\mathrm{TM}}$.

Stage Three: During this stage students converted their CAD solid models to a 3D print-compatible format and submitted them for printing. Students were financially responsible for their printing cost. The flat-rate cost per student (\$8.00 CDN) was approximately one-third of the regular price due to a subsidy by the material supplier.
There are techniques and limitations for any means of fabrication, whether by computer numeric control (CNC), manual machining, or 3D printing. These influence design and the students learned to be aware of this. Instructions and guidelines were provided at each stage of the activity to ensure final designs would be compatible with the limitations of 3D printing. To give students a tactile feel for what a 3D print is like, a small representation of typical shapes that might be used with their designs was printed, in the same material that they would use. This was passed among students so they could bend, twist and get a "hands-on feel" for the strength and stiffness of these shapes (Fig. 2).

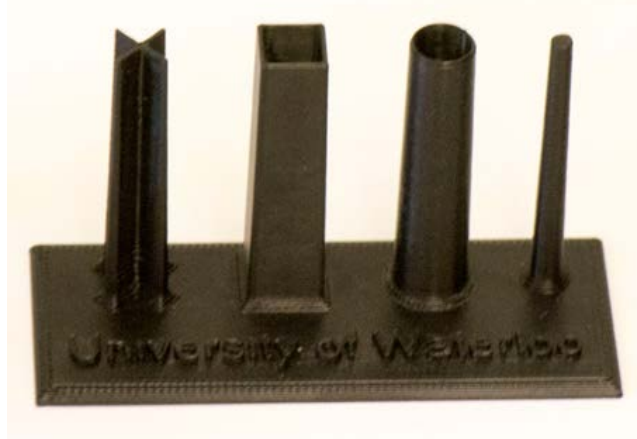

Fig. 2. 3D print of common shapes

\subsection{D Printing}

The 3D printing portion of the project began with a short presentation to the class by the co-op student operator at the 3D Print Centre to explain the 3D print process. He also provided guidance on design for additive manufacturing. Once the students had completed their 3D CAD models and converted their files to the correct format as instructed, they indicated their desire to see their models printed by paying the flat rate fee and uploading their models to a website. After this, the co-op student operator could review each model, provide feedback as required, accept the model for printing, and notify the student once printing was completed. This website, Lani, is being developed as a start-up company by a group of UWaterloo students.

The printing was completed over approximately a one week period (7 days x 24 hrs). This included uploading the files through a proprietary software interface to the 3D printers, printing the models, and removing the support material. (The FDM process uses a primary "build" material but also a second "support" material, as a stabilizing element to temporarily buttress the built structures and allow manufacturing of complex and hollow shapes.) This support material must be removed manually or by using a sodium hydroxide solution in a stirred, heated bath. Production of an average part takes 
about two days to be completed, from uploading the file to completing the parts washing process.

A challenge that arose during the printing process was that many of the models included excessive amounts of support material. In typical FDM printed parts, the support to build material ratio is approximately 1:3; however, many of the student designs required 2 and 3 times as much support as build material. This was due to the problem being under-constrained: the amount of build material was limited but the overall dimensions of the model were not. Many of the resulting designs were quite large and had small diameter, intricate features so that, although they stayed within the $2 \mathrm{in}^{3}$ build material constraint, the printing costs greatly exceeded what was anticipated. Furthermore, the final parts on some of the larger-size designs were very fragile and broke easily, especially during the cleaning process. This fragility has been recognized in the literature [13] (1 mm minimum wall thickness is recommended).

The 3D printing process was optional for the students and a total of 153 cell phone holders were printed. The maximum rate was anticipated to be 40 holders per day using all three Design Centre printers. Due to demands from other customers and larger than expected component sizes, the rate turned out to be 25 phone holders per day.

\subsection{From Conceptual Sketches to Fabrication}

As hoped, the 3D printer fabrication allowed a closedloop design process. Figure 3 shows one student example of the progression from sketch to a 3D printed end result.

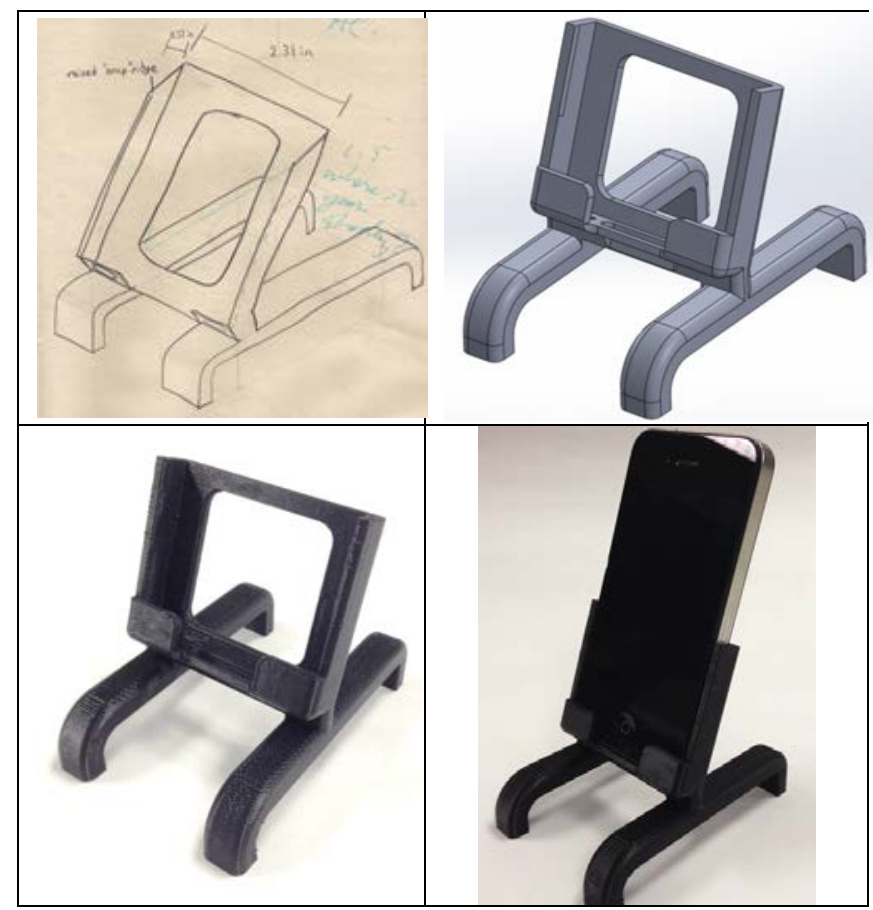

Fig. 3. Progression from sketch to 3D print.
Students crafted many creative designs (Fig 4.).

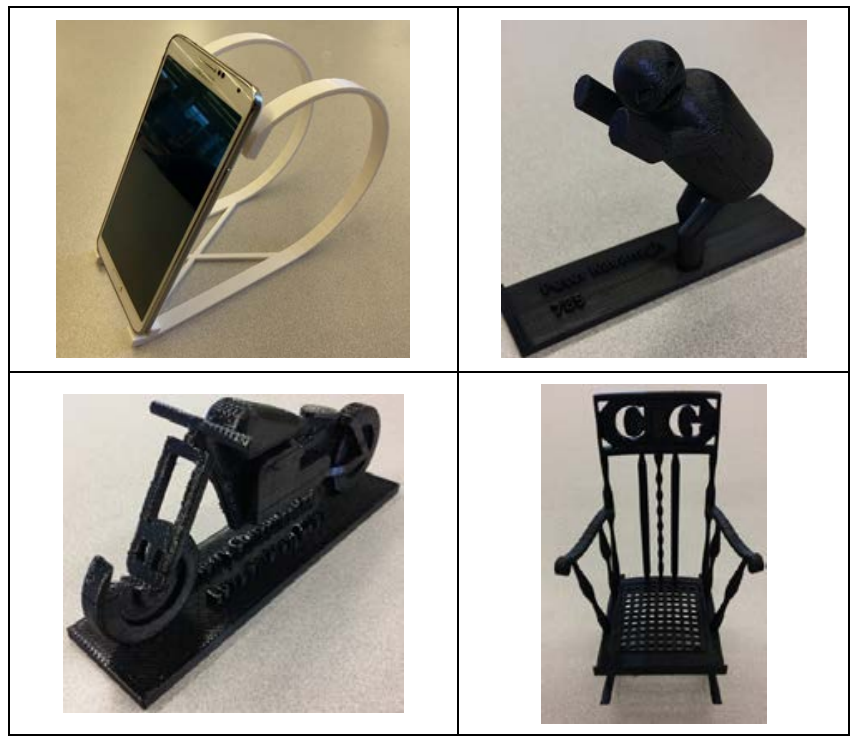

Fig. 4. A selection of student designs.

\subsection{Outcome Survey Results}

There were 81 students who completed the outcome survey. The initial questions asked if the project increased CAD expertise and whether students found the 3D printing experience worthwhile. The agreement to both questions was near unanimous (Fig. 5 and 6).

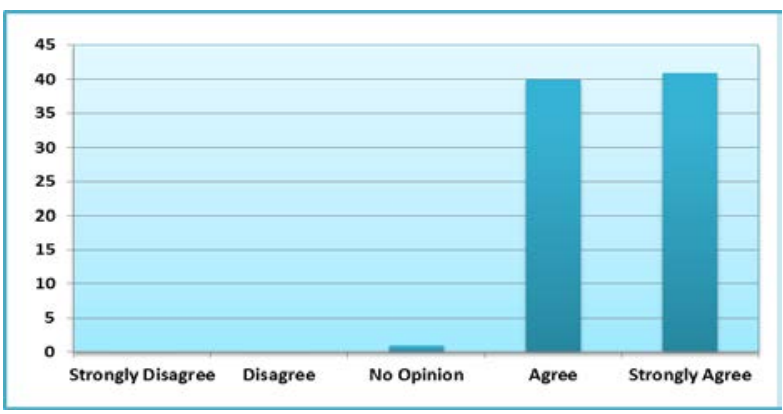

Fig. 5. This project extended my knowledge and expertise with SolidWorks ${ }^{\mathrm{TM}}$ (no. of students).

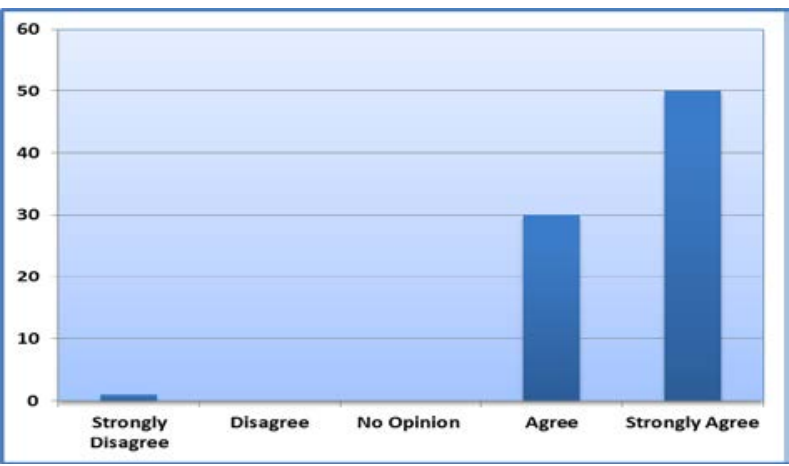

Fig. 6. It was worthwhile to obtain the printed model, as opposed to leaving the design at the CAD stage. 
The next question asked if students noticed differences between their perception of the CAD model and their physical prototype, a key assessment of this activity. The results: $70 \%$ of respondents discovered differences and $16 \%$ indicated that there were major variations (Fig. 7).

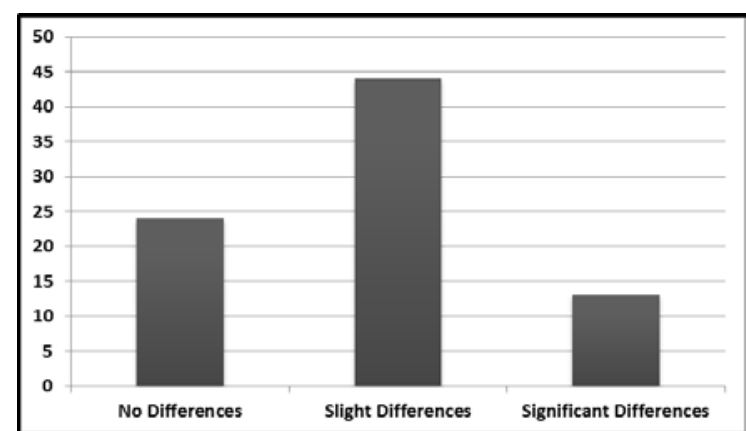

Fig. 7. Seeing/touching the printed model revealed differences from how I had perceived the CAD model.

Students were also queried if this activity prompted a future interest in 3D printing. This is an important outcome as the role of $3 \mathrm{D}$ printing in engineering is increasing. Result: 92\% agreed or strongly agreed (Fig 8).

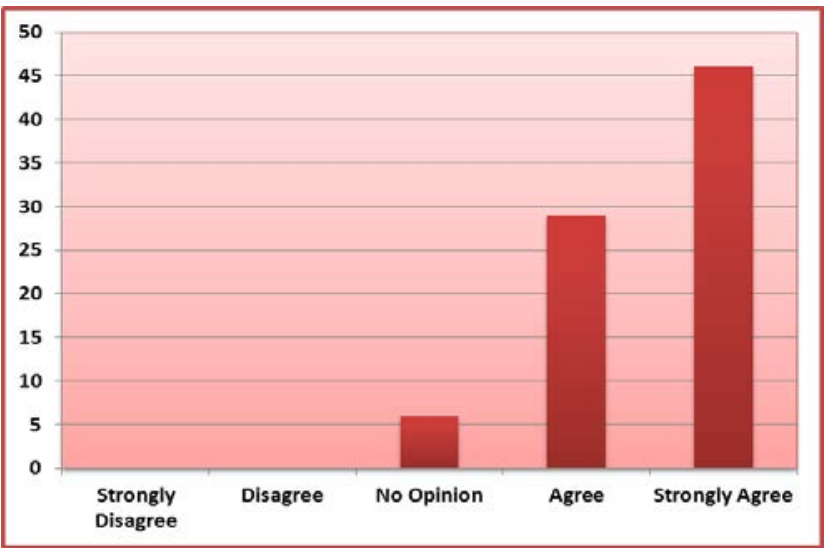

Fig. 8. Activity prompted further 3D printing interest.

The final graph shows that subsidized activity was important to $94 \%$ of the surveyed students (Fig. 9).

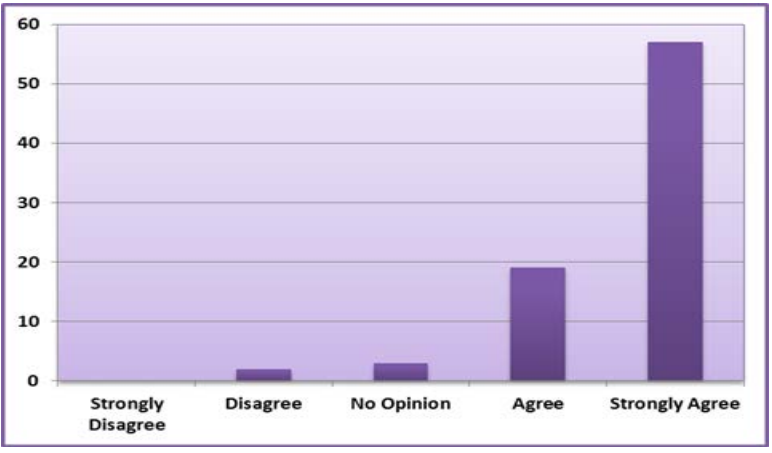

Fig. 9. The subsidized cost of the part was an important factor to make this project affordable. (no. of students)
The final survey question was a comment box that asked students for their opinion on why other students opted not to print their design. The comments included designs not meeting the volume constraint, lack of time, missing the due date, and "not realizing how awesome it would be".

\section{CONCLUDING REMARKS}

The route from design to fabrication is momentously simplified when that path goes to 3D printing as opposed to a traditional fabrication by machinist, or even to CNC machining processes. Furthermore, the shapes created for this project would be difficult to machine by traditional methods even for an accomplished machinist. It could be successfully argued that there is deeper learning when a student is responsible to fabricate the component they designed. This certainly has merit but it triggers a new level of resource requirements, supervision, safety training and expertise with machine tools during the first engineering term [12].

Fewer students took the opportunity to 3D print than expected, which was puzzling. It would be interesting to determine the cause(s), but measures can be enacted to increase this percentage (such as pointing out that this would make a good gift for a supportive parent).

There were a number of designs that were not stable with a cell phone in place. (An advantage of 3D printing is that it provides a "low cost" means of failure.) [12]. During future offerings, the students will be required to show a center of mass indication. This is useful as a precursor for later courses and easy to determine using the CAD software.

Once students have had an opportunity to physically examine their holder, it would be beneficial to have them list the revisions they would make for a second iteration of their design. This would promote a fuller completion of the design loop.

The students enjoyed this activity; the results of the outcome survey indicated their satisfaction and learning. However, it should be noted that the students who were surveyed were those that decided to 3D print.

An important outcome was to determine whether students perceived tangible differences between a CAD model (where many student designs are left off) and the fabricated component. The survey results revealed that this was the case. This bodes well for future uses of 3D printing as a means for reflective learning during the early years of engineering design education.

The 3D printing part of the project can be improved by including a constraint on the maximum dimensions of the model. By constraining not only the amount of build material but also the maximum length, width and depth dimensions, the amount of support material required will be reduced. This, along with the subsidized flat rate per student for printing and the corporate sponsorship, will be 
sufficient to cover all costs associated with this activity. Putting limits on dimensions will also speed up the printing process, allowing more models to be printed per machine operation cycle. The goal for the 3D Print Centre will be to support print models for the combined classes - up to 450 students - in the future.

\section{Acknowledgements}

The authors would like to gratefully acknowledge the contributions made by M. Austin, P. Burton, R. Figueiredo, C. Gravel, A. Morrison, C. Roy, Y. Sewlani, L. Stacey, S. Vriend, S. Walford, M. Wilson, and others.

The authors would also like to thank Stratasys for their generous donation of materials to this project, allowing our students to have affordable access to this learning opportunity.

\section{References}

[1] Kolb A. David, “Experiential Learning: Experience as the Source of Learning and Development”. Prentice Hall, Englewood Cliffs, New Jersey, 1984.

[2] Mark Morton and Katherine Lithgow, Experiential Learning from the Centre for Teaching Excellence, University of Waterloo. Retrieved April 2015 from //uwaterloo.ca/centrefor-teaching-excellence/resources/integrativelearning/experiential-learning

[3] Thomas Doyle, Spencer Smith and Adrian Ieta, "Closing the design loop in freshman engineering”, in Proc. American Society for Engineering Education ASEE 2011 AC 20112447

[4] Glen Livesay and Renee Rogge, "Vertical mentoring: closing the loop in design”, in Proc. American Society for Engineering Education 2006 ASEE 2006-2385

[5] Barry Berman, "3-D printing: The new industrial revolution”, Business Horizons, v 55, n 2, p 155-62, March-April 2012

[6] Nebojsa Jaksic, "New inexpensive 3D printers open doors to novel experiential learning practices in engineering education", in Proc. ASEE2014 American Society for Engineering Education. Indianapolis IN June 15-18 2014.

[7] James R. Baleshta, "Increasing student practical experience with the hurdle of large class sizes", in Proc. Canadian Engineering Education Association CEEA14 (Canmore, AB; June 8-11, 2014), 7 pp. 2014

[8] Polly Piergiovanni, "Creating a Critical Thinker”, College Teaching, 62: 86-93, 2014 Taylor \& Francis Group, LLC ISSN: 8756-7555 print / 1930-8299 online

[9] James Baleshta, Steve Lambert, Michael Collins, "Teaching Design using a Pharmaceutical Tablet Crusher Case Study”, in Proc. Canadian Engineering Education Association CEEA13 (Montreal QC; June 17-20, 2013), 10 pp. 2013

[10] William Bishop et. al., "Experiential learning activities: the Engineering Ideas Clinic experience, in Annual Teaching and Learning Conf. University of Waterloo April 30, 2015

[11] Stratsys, Four Ways 3D Printing is Shaping Product Design and Manufacturing, Design World Engineering White Papers, (C)2014 Stratasys Ltd. posted Jan. 16, 2015; www.engineeringwhitepapers.com/companies/stratasys/fourways-3d-printing-shaping-product-design-manufacturing

[12] Jessica McDonald, "3-D printing poised to change manufacturing, and the curriculum” ASEE First Bell, June 24, 2014. www.newsworks.org/index.php/local/item/696193-d-printing-poised-to-change-manufacturing-and-thecurriculum

[13] H.G. Lemu, "Study of capabilities and limitations of 3D printing technology", in Manufacturing Society International Conf. AIP Conf. Proc. v 1431, p 857-65, 2012 